\title{
UNAS BASES EPISTEMOLÓGICO-HERMENÉUTICAS PRÁCTICAS PARA LA COMUNICACIÓN INSTITUCIONAL
}

\author{
Reig, Ramón ${ }^{1}$ \\ Universidad de Sevilla (España) \\ ramonreig@us.es
}

Material original autorizado para su primera publicación en la revista académica REDMARKA. Revista Digital de Marketing Aplicado.

https://doi.org/10.17979/redma.2013.01.011.4808

Recibido: 15 Octubre 2013

Aceptado: 3 Diciembre 2013

\section{Resumen}

Este ensayo se escribe sobre la base del estudio e investigación universitaria y también a partir de la experiencia profesional en comunicación institucional. Parte de una preocupación del autor: la necesidad de que, en este caso, el comunicador institucional, al igual que todo periodista, debe poseer unas bases cognitivas amplias que son anteriores a la utilización de otras exigencias como

\footnotetext{
${ }^{1}$ Catedrático de Estructura de la Información Director de Ámbitos. Revista Internacional de Comunicación (www.ambitoscomunicacion.com) y del Laboratorio de Estudios en Comunicación (www.ladecom.es). Coordinador del Programa Internacional de Doctorado "Comunicación y Cultura en la Sociedad de la Información". Autor de numerosos libros entre los que caben citar: El control de la comunicación de masas (1995), Medios de comunicación y poder en España (1998), El éxtasis cibernético (2001), Dioses y diablos mediáticos (2004), La telaraña mediática (2010), Los dueños del periodismo (2011), Todo Mercado (2011) y Educación para el Mercado (Director) (2013). Ha ejercido quince años el periodismo en prensa, radio, productoras audiovisuales y gabinetes de comunicación.
} 
nuevas tecnologías o idiomas. No se debe descuidar la formación epistemológica en aras de una excesiva mecanización o servilismo a la cibernética porque el dominio del continente profesional puede resultar inútil sin la posesión de un buen "software" cultural.

Palabras clave: Conocimiento sincrónico, comunicación institucional, esfuerzo, estudio.

\section{Synopsis}

Along with university studies and researches, this essay is written based on true professional experience about institutional communication. It is motivated by the author's concern about the importance of having wide cognitive basis over other subjects as new technologies or foreign languages among institutional communicators (as well as any journalist). Epistemologic training must not be disregarded to avoid excessive "cybernetics-style" mechanization or subjugation. This kind of operational knowledge can be useless without having a proper "cultural software".

Keywords: Syncronic knowledge, institutional communication, effort, study.

\section{Resumo}

Este ensaio tem como base o estudo e investigação universitária, bem como a experiência profissional na área da comunicação institucional. Parte de uma preocupação do autor: a necessidade de que, neste caso, o comunicador institucional, da mesma forma que um jornalista, deve possuir bases cognitivas amplas, as quais são anteriores à utilização de outras exigências como as novas tecnologias e os idiomas. 
Não se deve descuidar a formação epistemológica em prol de uma excessiva mecanização ou servilismo da cibernética porque o domínio do conteúdo profissional pode ser inútil sem a posse de um bom "software" cultural.

Palavras-chave: Conhecimento sincrónico, comunicação institucional, esforço, estudo.

\section{Introducción}

Como se sabe de sobra la epistemología se ha encargado y se encarga de seguir las construcciones humanas del conocimiento. Pero, en nuestro caso, vamos más allá porque estudiar la construcción del conocimiento nos conduce a la "teoría evolutiva del conocimiento" que, según Erhard Oeser (1984, p. 247), no sólo se refiere al conocimiento humano sino también a la actuación humana bien sea en un sentido ético, moral, social y cultural. Llevar el tema del conocimiento más allá del campo descriptivo supone entrar en el campo de la hermenéutica si consideramos como tal explicar las relaciones existentes entre un hecho y el contexto en el que acontece.

En realidad, todo lo anterior no hace más que complicar el discurso ya que con sólo reflejar el concepto conocimiento sobran los demás. El mundo de hoy nos ofrece mucha información, Infoxicación (Alfons Cornella, en Reig, 2013, p. 344) o Infobesidad (Alvin Toffler, Francis Pisani) ${ }^{2}$. Como ya hemos afirmado en otras obras (Reig, 1995 y Reig, 2011), para decirlo con claridad, la información son las teselas o las piezas de un puzle. El conocimiento es el mosaico y el rompecabezas construido, de manera que pasemos así desde los datos sueltos al conocimiento sincrónico. Pero esto no es posible sin un esfuerzo de estudio

\footnotetext{
${ }^{2}$ Ver: http://www.elmundodewayne.es/2011/11/02/nuevos-horizontes-de-la-comunicacion-en-la-erade-la-digitalizacion-y-la-globalizacion/. Consultado, 15/10/2013.
} 
sobre la base de un método que, en nuestro caso, es el método estructural para el que la palabra Totalidad es clave.

\section{Supuestos}

Partimos de la base por tanto de lo que pudiera ser una especie de analfabetismo funcional consistente en una hiperinformación sin ordenar en nuestro interior. En el congreso internacional Infoxicación que se desarrolló en la Universidad de Sevilla (España) durante los días 20, 21 y 22 de noviembre de 2013, el doctor Fernando Figueredo, profesor de la Florida International University (Miami) y DirCom del alcalde de la citada ciudad, afirmó que el cerebro humano puede soportar al día unos 20.000 mensajes diferentes. Ya en nuestra tesis doctoral -en 1994, publicada después casi toda ella ese mismo año y en 1995- insistimos en que este fenómeno conduce a lo que entonces llamamos "efecto de hibernación", es decir, a una paralización de la actividad humana puesto que el exceso de datos confunde y una mente confusa y embotada deviene en paralización de la actividad.

El comunicador institucional se enfrenta en la actualidad a un trabajo que, al mismo tiempo, ha cambiado mucho pero no ha cambiado nada. Mucho por la presencia de la sociedad web 2.0 y la 3.0 -que será más compleja, semántica e incluso doctrinaria- toda ella construida en torno a las nuevas tecnologías en continua evolución. Poco porque su trabajo sigue consistiendo en "vender" un producto, se llame persona, líder, candidato o institución pública o privada.

Sin embargo, el cambio en las herramientas de trabajo ha traído consigo una terminología que lo inunda todo e incluso se presenta como el símbolo de las mejores salidas profesionales en comunicación. Cada vez es más frecuente oír expresiones en inglés tales como: DirCom, Social Media Manager, Community Manager, Social Networking, Branding 2.0... No nos vamos a detener en el significado de tan intensa y machacona retahíla sino en lo que debe precederla 
que es, ni más ni menos, que una buena formación cultural por parte del profesional institucional que, ciertamente, corre el riesgo de perderse en este nuevo grado académico-cibernético que puede atraparte entre sus piezas continentales.

Pero si, según el dicho popular, el que es ignorante en un idioma es ignorante en todos los idiomas que aprenda, el comunicador institucional que domine, más o menos, las nuevas corrientes de emisión y recepción pero no posea una base cultural sólida de conocimiento sincrónico, puede llevarse la sorpresa de que el desarrollo de su trabajo cuanto menos cojea y, lo más grave, puede fracasar.

Por tanto, nos interesa recordar, desde la experiencia profesional y el estudio, algunos extremos formativos que deben ser previos al enfrentamiento cotidiano con la cibernética. Serán simples anotaciones prácticas sobre las que asentar un ejercicio profesional más riguroso o, sencillamente, riguroso.

\section{El método}

Lo primero es el método para intentar entender lo que ocurre. Ya hemos apuntado que el nuestro es el método estructural que, con la máxima brevedad, se define así: Todo está relacionado con todo. Es un Todo mayúscula que llega a relacionarse con el todo minúscula y al revés, o sea, el conocimiento sincrónico, la hermenéutica más compleja, exige acudir a la evolución de Todo desde el Todo al todo y desde el todo al Todo. Desde este enfoque, la Historia de la Humanidad no comienza en la prehistoria o en las primeras civilizaciones sino en el Big Bang considerándola, en nuestros días, como una teoría generalmente aceptada.

En efecto, en 2004 los diarios El País y Abc, ambos de España, lanzaron como ganchos promocionales sendas historias universales. Pero mientras el volumen primero de la de $A b c$ versaba sobre el clásico y manido tema de las primeras 
civilizaciones, el de El País comenzaba por un capítulo titulado "Nuestro planeta antes de la aparición de la vida". Recientemente se ha llegado más lejos. History Channel emitió en 2012 un interesante documental titulado La Historia del Mundo en dos horas que abarcaba "desde el Big Bang hasta el tiempo presente", afirmaba la voz el off y añadía: "Todo está conectado y el sendero llega hasta ustedes". ${ }^{3}$

No es que le vayamos a pedir al comunicador institucional una formación tan vasta pero sí que no olvide por dónde camina en la actualidad el conocimiento, que tenga en cuenta hasta dónde llega el contexto inductivo-deductivo. En nuestro libro La telaraña mediática (2010) explicábamos parte del método estructural mediante lo que llamamos la metáfora de la pirámide maya y esa explicación sí estaba más acotada a lo mediático y su entorno, por tanto, sí es de interés cognitivo para el profesional de la comunicación institucional en particular y para el comunicador en general. Afirmábamos entonces:

En 1999 viajamos a la Universidad de Yucatán (México), a impartir un curso de Doctorado. La universidad, dentro del capítulo de actividades complementarias, tuvo la amabilidad de llevarnos, entre otros lugares, a visitar las ciudades mayas de Uxmal y Chichén Itzá. Subimos a las pirámides escalonadas visitables de estas ciudades. Los peldaños no son demasiado anchos -más bien al contrario- y cuando se ha llegado al final, se observan dos factores clave: uno, al mirar hacia abajo, los escalones se han convertido en una especie de cuesta abajo muy empinada en la que los peldaños por los que hemos ascendido no se distinguen apenas; dos, desde la parte alta de la pirámide aparece ante nuestros ojos todo un paisaje boscoso, el bosque bajo típico de aquel lugar. Más lejos, el bosque se va diluyendo hasta terminar. El resto del paisaje -ya lejano- es invisible e inabarcable.

\footnotetext{
${ }^{3}$ Véase: http://www.youtube.com/watch?v=GOEy5ahVJEc. Consultado en septiembre de 2013.
} 
Los peldaños son los medios de comunicación, los elementos inductivos por los que vamos ascendiendo hacia la totalidad mediática. Desde la totalidad se puede contemplar escasamente la imagen de los peldaños, que se funden en una sola imagen: la totalidad nos dificulta ver los elementos peldaños pero, no obstante, siguen ahí: existen. La totalidad difumina parcialidades pero no las destruye. El bosque es el contexto que rodea a la totalidad: podemos distinguir árboles pero no otros muchos vectores. El paisaje boscoso más oculto, y el más lejano, representa las zonas no visibles de una estructura. Sería preciso acercarse a ello para intentar desentrañar sus contenidos y significados. En realidad, tanto lo más visible como lo menos observable encierra la necesidad del estudio para el científico. Más o menos lejos, más o menos oculto, todo está ante nosotros configurando una totalidad. Pero hay que sumergirse en ella para intentar comprenderla.

Hasta aquí una mera aproximación al método que proponemos. Centrémonos ahora en unos apuntes igualmente prácticos para intentar lograr una base cultural apta para ejercer la comunicación institucional. No olvidemos que el comunicador institucional es algo más que un periodista: es un asesor de bajos, medios o altos cargos que debe saber -incluso antes que sus "superiores"- lo que está ocurriendo en el espacio contextual más amplio que pueda abarcar. $Y$, repetimos, para eso se precisa esfuerzo y estudio porque estamos ante una profesión-oficio que se puede prolongar las veinticuatro horas del día/noche.

\section{Un asesor en Comunicación debe hacer a diario...}

- Nada más despertar, conectarse a la radio. Escuchar distintos informativos de diversas tendencias. El asesor en comunicación no es lo que llamamos un ciudadano de a pie, esos públicos que persiguen que 
los medios les digan lo que desean escuchar. Por el contrario, se trata de un profesional.

- Escuchar tertulias y ver algún programa matinal informativo en TV.

- Dedicar unas dos horas a la lectura de prensa. Es una tarea obligatoria a primerísima hora de la mañana y/o a últimas horas de la noche, antes de ir a la cama. A pesar de las particularidades de la información audiovisual, la información escrita, en prensa, sigue produciendo ese efecto de arrastre en los demás medios y mucho más cuando se trata de prensa de referencia. Una vez documentado:

- Despachar con su equipo y con sus superiores. Orientarlos a todos y dar una primera visión interpretativa de la actualidad.

- Departir con periodistas a través de medios cibernéticos y/o personalmente.

\section{Un asesor en Comunicación debe saber...}

Repetimos: antes, o al mismo tiempo, de utilizar las nuevas herramientas cibernéticas, el comunicador institucional está obligado a conocer e interpretar diversos aspectos, entre ellos:

- Que la obligación de toda estructura de poder es prolongarse en el tiempo, a veces con medios de dudosa reputación.

- Que el ser humano se mueve sobre todo por emociones.

- Que en el mundo todo se compra y se vende.

- Que la mejor metodología para entender el mundo y la vida cotidiana es el enfoque estructural. 
- Que él es un emisor hacia la sociedad de la actualidad de algún poder pero que sus mensajes han de pasar por sus colegas periodistas.

- Que el mundo de la información y la comunicación es una inmensa tela de araña cargado de intereses.

- Que el bipartidismo mundial se extiende al periodismo.

- Que, por regla general, es un agente emisor de mensajes en el seno de un sistema único de mercado.

- Que existen dos tipos de mensajes constatables: el estructural y el coyuntural (Reig, 2010). El estructural hace referencia a esa uniformidad esencial del mensaje cuando se trata de defender el orden occidental (el mensaje frente a las actuaciones de Cristina Fernández de Kirchner, Evo Morales, Irán o Corea del Norte). El coyuntural lo tenemos a diario en los medios: es la "batalla" política y las investigaciones y filtraciones sobre el sector público, no sobre el privado que, a pesar de ser el Poder más importante, es escasamente criticado y menos cuestionado.

- Que existen dos tipos de discursos en el poder: el de puertas afuera y el de puertas adentro.

- Que el poder es poder porque utiliza estos dos discursos y no descubre sus cartas más esenciales.

- Que tal vez el político que está "arriba" posea "traumas" psicológicos. El enfoque estructural psicológico y psicohistórico -tan escaso- es sin embargo clave para entender los hechos.

- Que el carisma, si no se tiene, es muy difícil de construir.

- Que los tristes no suelen ganar las elecciones. 
- Que el receptor es medroso, por regla general. Huye de la confusión como, por ejemplo, de los partidos en crisis o de movimientos como el 15-M que, al final, ha demostrado que detrás sólo tenía humo y buenas intenciones.

- Que el Poder debe proyectar positividad.

- Que el ciudadano busca sobre todo que le digan lo que desea oír. Como indica Antoni Gutiérrez-Rubí (2009), cuando nuestro cerebro percibe una explicación distinta a lo que él cree, corta los circuitos de comunicación para que no penetre.

- Que, en momentos de crisis, la sinceridad y la humildad pueden dar buenos resultados.

- Que el receptor no es absolutamente manejable.

- Que la información "o la haces" o "te la hacen". El periodista que es enviado a elaborar una información busca fuentes. Si se evita atenderlo, trasladará su quehacer a otras partes con lo que se pierde el "control" de su trabajo.

- Que la primera impresión es la que queda.

- Que los periodistas no son sus enemigos.

- Que debe efectuar un seguimiento continuo de las actividades de los "amigos" y de los "rivales".

- Que debe poseer fuentes de información propias.

- Que debe contar con un buen servicio de documentación.

- Que debe preparar a sus superiores para "enfrentarse" a la prensa y a sus rivales en general. 
- Que no puede traicionar su deontología convirtiéndose en cómplice de presuntas irregularidades de sus superiores y/o de su institución.

- Que la transmisión del mensaje se basa en constantes psico-biológicas "de siempre": sencillez, repetición, imitación, color, sonido, movimiento.

Una vez anotadas estas orientaciones que consideramos básicas vamos a intentar articular algunas de ellas aplicando el método estructural del que tratábamos más arriba.

\section{Un enfoque estructural para la Comunicación Institucional}

\subsection{Poder y mundo mediático}

Le hemos recordado antes a un potencial profesional de la comunicación institucional que la obligación de toda estructura de poder es prolongarse en el tiempo, a veces con medios de dudosa reputación. Eduardo Punset (2005, p. 103) afirma:

A los ciudadanos que dan por sentado el privilegio de vivir en sociedades donde se controla al poder político, les cuesta imaginar la brutalidad con que se ejerció el poder desde sus albores hace quince mil años. Las posturas desgarradas de los restos fósiles de sacrificios humanos, el transporte de piedras monumentales a kilómetros de distancia, las guerras tribales de los pueblos primitivos que -en las tribus de las que se tienen registros como los Jíbaro y Yanomano de América Latina- implicaban el exterminio de la mitad de su población masculina, constituyen indicios escalofriantes del ejercicio abyecto del poder político. 
Ahora bien, lo que sostenemos es que la constante persiste y que el hecho Poder en la actualidad sigue ahí aunque, como suele decirse, corregido y aumentado. En nuestro trabajo Educación para el mercado (2013) hemos representado de esta manera al Poder actual:

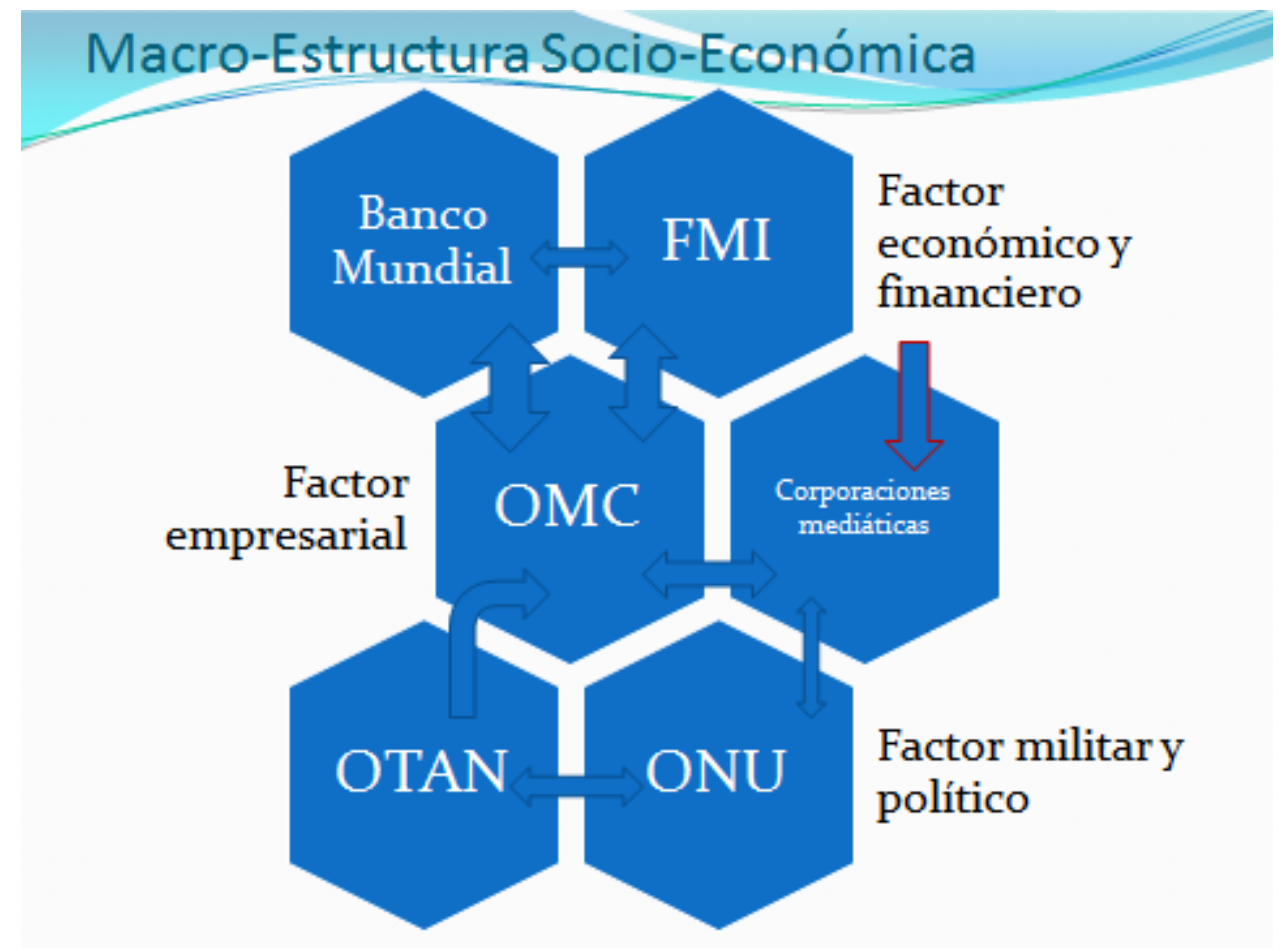

Es decir, aquel poder despiadado de otros tiempos (por desgracia aún visible en algunos lugares del planeta) en nuestros días se encuentra articulado en un factor económico-financiero, otro empresarial y otro político militar. El Poder actual se llama Mercado, algo que es válido incluso para países como China. En el interior del Mercado los elementos o factores que lo conforman están en conflicto pero eso es algo lógico en todo colectivo humano y aún más si el colectivo ha alcanzado una mundialización tan compleja como la de hoy. La ONU ya no tiene a la URSS para vetar decisiones; la OTAN no se enfrenta al Pacto de Varsovia, el FMI y el BM intentan gestionar el buen funcionamiento 
del Poder con una influencia decisiva de los Estados Unidos que, aunque en realidad sea un gigante con los pies de barro, goza del favor y el respeto de los demás poderes de mercado. China y Rusia compiten por los mercados, no por implantar nuevas estructuras socioeconómicas y nuevas éticas de comportamiento.

Todo este poder actual precisa de unos elementos sustanciales para intentar cumplir esa misión de perpetuarse: los mensajes, algo que es competencia de las corporaciones mediáticas, sobre todo, y de los grandes grupos mediáticos en general, unidos o no a ellas.

Es preciso tener en cuenta que el empresario "puro" de medios de comunicación apenas existe ya en el mundo occidental. En Sevilla (España), en noviembre de 2013, el diario decano de la ciudad, El Correo de Andalucía, nacido en el siglo XIX, fue adquirido por el Grupo Morera \& Vallejo cuyos negocios no están en la comunicación sino en el sector seguros y reaseguros, agricultura, ganadería, hostelería y alquiler inmobiliario. Aunque de origen sevillano, el grupo tiene presencia en Europa y América en general. Antes de esta compra, El Correo de Andalucía había estado, entre otras, en manos del Grupo Gallardo cuyo objeto social principal es el sector siderúrgico.

En España existe un duopolio audiovisual formado por los grupos mediáticos Atresmedia (propiedad sobre todo del Grupo Planeta e indirectamente de Televisa, de México) y Mediaset España, cuyos principales accionistas, directos e indirectos, se pueden observar en la ilustración siguiente: 


\section{MEDIASET España.

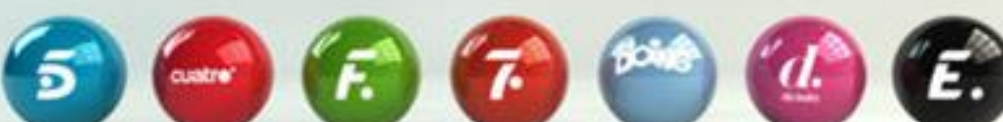

Propietarios principales (directos o indirectos)

Prisa.

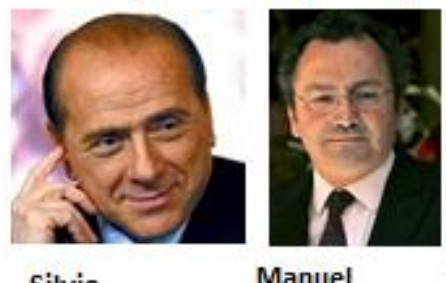

Silvio

Manuel

Berlusconi,

exprimer

ministro de

Polanco,

magnate español del

Grupo

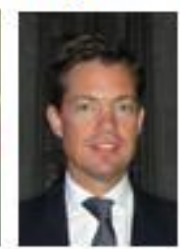

Nicolas

Berggruen,

presidente

de

Italia

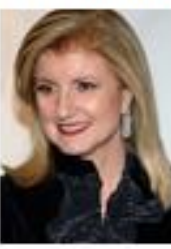

Arianna

Hufftington,

AOL.

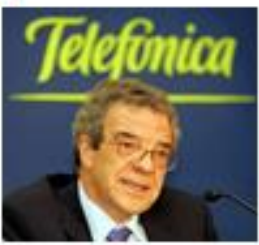

César Alierta, presidente de Telefónica, participada por Caixabank.

Observamos la presencia de Berlusconi (medios, banca, supermercados, deportes, política...), Liberty (un fondo de inversión estadounidense representado por Berggruen), America On Line (AOL) y Telefónica, participada a su vez por la banca española (BBVA, por ejemplo).

Se trata de la forma de desenvolverse de un poder que es consciente de que posee amplios altavoces con los que, si no convencer, al menos, hacer dudar a la opinión pública porque una opinión pública que duda es una opinión pública que no actúa porque está afectada por el “efecto de hibernación” (Reig, 1995).

Veamos otros ejemplos paradigmáticos de conexiones entre medios/grupos de comunicación y corporaciones financiero-empresariales:

\begin{tabular}{|l|l|}
\hline Grupos/medios de comunicación & $\begin{array}{l}\text { Corporaciones que los controlan } \\
\text { HSBC (GB), Deutsche Bank (D), Bank } \\
\text { of America (USA) }\end{array}$ \\
\hline Corriere Della Sera (I) Unidad & Fiat (I), Pirelli (I) \\
\hline
\end{tabular}




\begin{tabular}{|l|l|}
\hline Editorial/El Mundo (E) & \multicolumn{1}{|c|}{} \\
\hline Vocento (E) & $\begin{array}{l}\text { E.ON España (D), BBVA (E), } \\
\text { Santander (E) }\end{array}$ \\
\hline The Independent (GB) & $\begin{array}{l}\text { Alexander Lébedev (Aeroflot, banca, } \\
\text { agroindustria...) (Rusia) }\end{array}$ \\
\hline NBC (USA) & General Electric (USA) \\
\hline
\end{tabular}

Elaboración propia, 2013, sobre datos de Reig, Ramón (2011): Los dueños del periodismo, Barcelona, Gedisa, y archivos propios.

La deuda que en el primer semestre de 2013 mantenía Prisa (3.100 millones de euros, aproximadamente) con diversos bancos, ha provocado que la banca cambie deuda por acciones. Es así como una serie de entidades financieras citadas en el cuadro- más otras como La Caixa, han logrado cada una de ellas alrededor del 3\% del capital del grupo. Si consultamos la cartera de clientes de todos los bancos citados, encontramos entidades como Gas Natural, Telefónica, Repsol o Abertis, en el caso de La Caixa ${ }^{4}$. Y anotamos sólo un mínimo ejemplo.

Fiat no fabrica sólo automóviles sino también misiles Patriot para los ejércitos occidentales (Pascual Serrano, 2010). Su vinculación mediática es conocida desde hace años en los mercados italiano y español. A su vez, si la familia Agnelli es la propietaria principal de Fiat, la empresa cuenta con accionistas secundarios como Pirelli o Mediobanca.

En el consejo de administración que en 2012 constituyó el grupo Vocento (resultado de la unión en 2001 de Prensa Española/ABC y del grupo Correo), estaban los siguientes nombres, entre otros:

- Enrique de Ybarra Ybarra, Presidente del Consejo. Vinculado al BBVA.

- Miguel Antoñanzas Alvear, presidente y consejero Delegado de E.ON España (energía, filial de la alemana E.ON, de capital público).

\footnotetext{
${ }^{4}$ http://www.hispanidad.com/Exclusivas-prensa/la-caixa-estudia-crear-un-gran-hlding-con-susparticipadas-20130429-156278.html, 28/4/2013.
} 
- Rodrigo Echenique Gordillo, consejero del Banco Santander.

El magnate ruso Alexander Lébedev, ex miembro del KGB soviético, controla, entre otros medios, el diario inglés The Independent. Lébedev es el mayor cultivador de papas de Rusia y posee acciones en la aeronáutica Aeroflot, entre otros intereses. Por último, la empresa General Electric -que fabrica desde un frigorífico hasta armamento, pasando por satélites- controlaba la NBC en el primer semestre de 2013. NBC está unida desde 2010 al grupo Comcast (USA), especializado en televisión por cable.

Queremos decir que el mundo mediático se encuentra insertado en la propia economía de mercado, es la economía de mercado, o sea, el Poder, no es el cuarto poder ni el contrapoder sino un elemento clave para el Poder: el que se encarga de emitir mensajes que prolonguen la duración del poder. Esto no quiere decir que el 100 por 100 de los mensajes sean "doctrinarios". Pueden hallarse mensajes antisistema en los medios del sistema. Pero serán la excepción que confirme la regla y que permite al Poder auto-legitimarse como pluralista.

Tampoco estamos condenando abiertamente y de forma apocalíptica esta realidad, simplemente la describimos en una mínima parte y afirmamos: muy bien, así funciona la economía de mercado, está en su derecho y crea dichas y problemas. Pero permítanme que, como investigador universitario, como periodista y como ciudadano, exprese mi serio temor a que toda esta dinámica esté dinamitando lo que llamamos democracia.

\subsection{La proyección del mensaje}


El Poder va a necesitar una estrategia proyectora de mensajes para intentar perdurar todo lo posible en el tiempo. Es de especial interés que en comunicación institucional se sea muy consciente del aspecto psicobiológico en relación con el mensaje. Ya se ha apuntado antes la importancia de las emociones en el ser humano. De forma simplificada, la trayectoria de un mensaje puede representarse así:

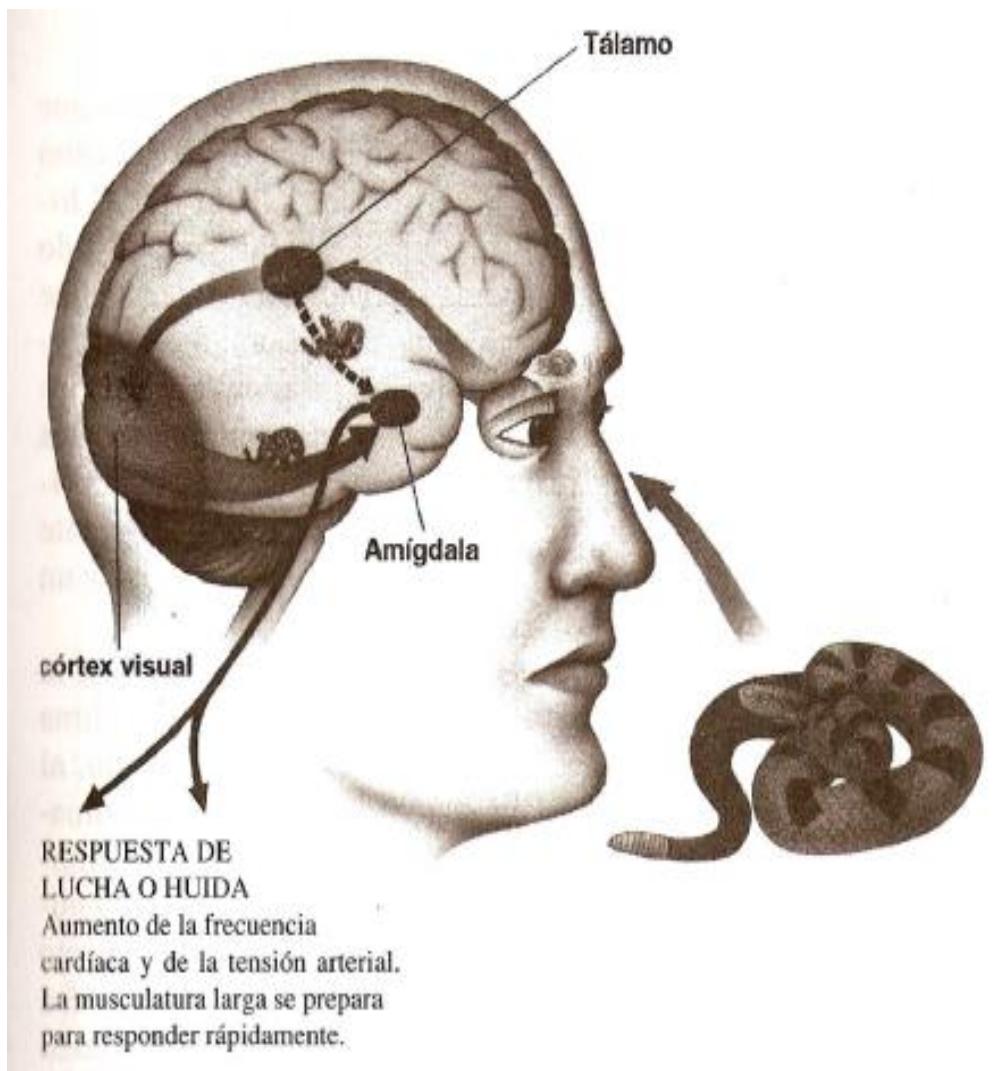

Una señal visual va de la retina al tálamo, en donde se traduce al lenguaje del cerebro. La mayor parte de este mensaje va después al córtex visual, en donde se analiza y evalúa en busca de su significado para emitir la respuesta apropiada. Si esta respuesta es emocional, una señal se dirige a la amígdala para activar los centros emocionales, pero una pequeña porción de la señal original va directamente desde el tálamo a la amígdala por una vía más corta, permitiendo una respuesta más rápida (aunque ciertamente más 
imprecisa). De este modo la amígdala puede desencadenar una respuesta antes de que los centros corticales hayan comprendido completamente lo que está ocurriendo. (Joseph LeDoux, en Goleman, D. (1996): Inteligencia emocional, Barcelona, Kairós.)

Sin duda, el Poder (y dentro de su estructura suele estar casi toda la comunicación institucional) hace suyas estas ideas (Gutiérrez-Rubí, 2009):

- Las razones no siempre dominan al corazón.

- Tomamos decisiones muy serias e importantes con un gran nivel de exposición a la equivocación.

- La mejor manera de llegar al cerebro de un elector es a través de su corazón.

- Preferimos las convicciones emocionales o morales a las confirmaciones racionales o epistemológicas.

En relación concreta con el proceso de formación de la opinión pública, Octavio Uña Juárez, Maximiliano Fernández Fernández y Carmen Fernández Camacho (2013, p. 81), indican:

El proceso dinámico de la formación de la opinión pública puede dividirse en cuatro etapas interdependientes y complementarias entre sí. En la primera etapa, existe un tema o problema que compromete a la sociedad o a una parte de ella. Este problema, no obstante, no se ha definido como tal ni sus posibles consecuencias. En la segunda, se producen consideraciones preliminares acerca de ese tema. El grupo propondrá líneas de acción como respuesta al problema. La tercera etapa se caracteriza por ser el momento en el que se presentan soluciones alternativas. Por último, la cuarta etapa involucra intercambios de toda índole facilitando que los individuos puedan 
alcanzar cierto consenso. Precisamente, es en la tercera etapa cuando el individuo toma decisiones más comprometidas, cuando la conducta del individuo se transforma en una conducta de masas, lo que implica que aspectos racionales del problema ocupen un segundo plano siendo las apelaciones emocionales las que alcancen el protagonismo.

Es conocido que las emociones - para ser despertadas en pro de un fin funcional del mensaje- precisan de la claridad y de la simplicidad. También en el trabajo que dirigimos y elaboramos junto a un nutrido grupo de investigadores de cuatro departamentos de la Universidad de Sevilla y que ha aparecido bajo el nombre de Educación para el mercado (2013) hemos dado a conocer lo que denominamos "El paradigma Pocoyó". Está basado en la serie infantil Pocoyó y puede representarse así:

\section{El paradigma Pocoyó}

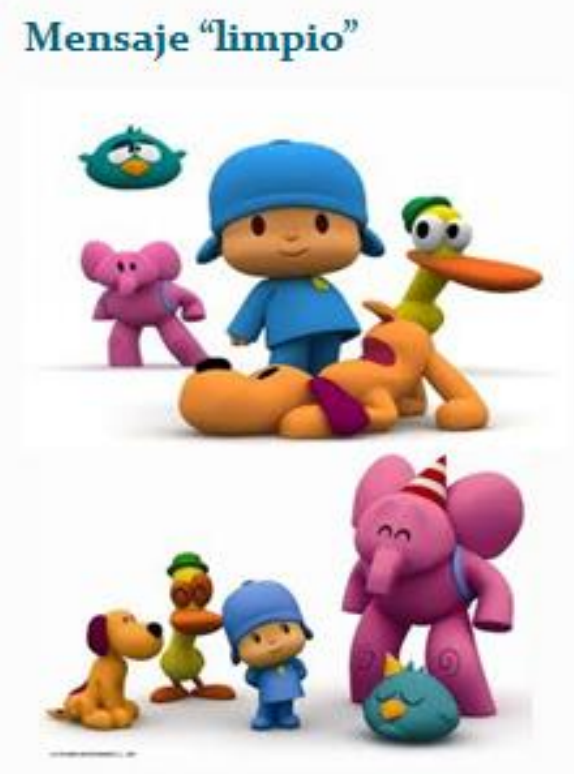

Características inmediatas

- Fondo blanco (apenas perceptible).

- Focalización de la mirada.

- Focalización del pensamiento.

- Lo exento contra lo barroco.

- Centralización del personaje principal.

- Liderazgo positivo.

Colaboración intergrupal.

- Colores vivos pero no agresivos.

- Movimiento.

- Sonido optimista sin estridencias.

- Conclusión: sencillez y claridad.

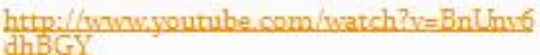

REDMARKA UIMA-Universidad de A Coruña - CIECID

Año VI, Número 11, (2013), v1 pp. 99-123

http://www.redmarka.org/

ISSN 1852-2300 
No obstante, el proceso es aún más complejo desde la irrupción de nuevas formas de estudio científico acerca del comportamiento del ciudadano que es estudiado a la vez que puede ser conducido mediante el estudio de su conducta y de su cerebro. Una de esas ciencias relativamente jóvenes es la Neuroeconomía. Valentín-Alejandro Martínez-Fernández y Oscar JuanateyBoga (2013, p. 117) sostienen:

La Neuroeconomía, concebida como disciplina, cobra carta de naturaleza propia en los primeros años de la última década del pasado Siglo. Consecuencia del cuestionamiento del modelo neoclásico formulado por la llamada economía del comportamiento, conforme al cual los principios que determinan la elección no se sustentan exclusivamente en la racionalidad de la persona, a lo largo de los últimos años ha experimentado un inusitado desarrollo debido, entre otras causas, a la aplicación de las nuevas y sofisticas tecnologías y herramientas propias de las neurociencias y que han permitido experimentar un salto cualitativo en cuanto a conocer el funcionamiento del cerebro, de modo que éste, para la economía, ha dejado de ser la inescrutable «caja negra» que impedía comprender determinados comportamientos. $Y$ es en el estudio de los comportamientos humanos, centrado principalmente en la figura del consumidor, donde a partir de la Neuroeconomía ha surgido una nueva disciplina cual es el Neuromarketing, cuyo desarrollo abarca no sólo el campo científico y académico sino también el empresarial.

Las raíces más inmediatas de todas estas cuestiones ya es sabido que las hallamos en Freud (2007). Recordemos también, por tanto, sus principios más relevantes: 
- La masa tiene que hallarse mantenida en cohesión por algún poder: el Eros, "que mantiene la cohesión de todo lo existente".

- La masa se deja sugestionar por los otros para hallarse en cohesión con ellos y no en oposición a ellos.

- Más que un animal gregario el hombre es un animal de horda conducido por un jefe.

- El Ejército y la Iglesia ofrecen el ejemplo de una horda amplia de individuos que necesitan ser amados por un jefe: el superhombre de Nietzsche, que no necesita amar a nadie.

- El jefe es considerado superior pero ellos se consideran iguales.

Toda esta dinámica origina las relaciones emocionales con su influencia sobre las decisiones y los pensamientos de los seres humanos. "El poder inteligente sonríe, no amenaza. Así se ganan las nuevas batallas", afirma Gutiérrez-Rubí (2009).

Carlos Castilla del Pino (2000, p. 342) constata que "los sentimientos son emociones" y que "el límite entre emoción y sentimiento es imprecisable". Pero advierte que "las respuestas viscerales son bastante comunes en experiencias emocionales varias" (2000, p. 25). Por consiguiente, es preciso tener en cuenta que la utilización emocional por parte de los mensajes del Poder en ocasiones puede írsele de las manos al propio Poder, sin que ello invalide la indudable realidad y utilidad de la relación Poder-Mensajes-Emociones, una relación que en nuestro tiempo -y en lo que a comunicación institucional se refiere- puede y debe tender aún más a la simplicidad y a lo sintético puesto que ahora nos hallamos en el seno de la comunicación fragmentada, donde prima lo instantáneo, lo inmediato, lo fugaz, como en el uso común de las redes sociales. 
Tal vez, con el tiempo y el paso de las generaciones, el uso de las redes cambie hacia una cualificación mayor (algunos síntomas se ven en los llamados nativos digitales, según Urs Gasser, 2012, pp. 95-96) pero, hasta ahora, le realidad del uso de las nuevas tecnologías nos muestra un público a la vez unido y fragmentado que se entretiene y crea su propia comunicación epidérmica en la Red y a velocidades que apenas permiten conocer aquello de lo que se trata o a lo que se accede. Se "juega", se experimentan emociones pero el conocimiento aparece en mucha menor medida.

\section{Conclusión}

En definitiva, un paso previo al manejo de las nuevas herramientas que permiten ampliar el significado y el ejercicio profesional de la comunicación institucional, consiste en que es imprescindible que el comunicador dedicado a esa especialidad posea un poso cognitivo sobre la base del enfoque de la totalidad o estructural. Dicha formación no podrá cesar nunca y deberá acompañar al dominio de las técnicas de trabajo. La base cognitiva sincrónica nos permitirá considerarnos y ejercer como profesionales expertos. Las técnicas cibernéticas de trabajo se unen a lo anterior pero ya forman parte del aspecto más técnico -si se nos permite la expresión- del oficio.

\section{Referencias}

- Castilla del Pino, Carlos (2000): Teoría de los sentimientos, Barcelona, Tusquets. 
- Edwards, D.; Cromwell, D. (2006): Guardians of power: the myth of the liberal media. London, UK, Pluto Books.

- Freud, Sigmund (2007): Psicología de las masas, Madrid, Alianza Editorial.

- Gasser, Urs (2012): "Las nuevas tecnologías de la información y la educación de la juventud" en Moragas, Miquel de y otros: La comunicación: de los orígenes a Internet, Barcelona, Gedisa.

- Goleman, Daniel (1996): Inteligencia emocional, Barcelona, Kairós.

- Gutiérrez-Rubí, Antoni (2009): La neuropolítica: conocer el cerebro para liderar las ideas, disponible en: http://www.gutierrez-rubi.es/wpcontent/uploads/2009/11/revistafrc la neuropolitica.pdf

- Martínez-Fernández, Valentín-Alejandro y Juanatey-Boga, Oscar (2013): "Neuroeconomía y Neuromarketing.: Estado de la cuestión de las relaciones entre Neurociencias, Marketing y Economía", en Álvarez, Jesús Timoteo (Investigador Principal): Neurocomunicación: Gestión de la Comunicación Social basada en las Neurociencias, Proyecto de Investigación CSO2011-28099. Informe 2012 Plan Nacional de I + D, Ministerio de Economía y Competitividad: Secretaría de Estado de Investigación, Desarrollo e Innovación.

- Meyer, Thomas (2002): Media democracy: how the media colonize politics, en: http://www.lavoisier.fr/livre/notice.asp?ouvrage=1536789.

- Oeser, Erhard (1984): “La evolución del método científico", en Lorenz, Konrad y Wuketits, Franz: La evolución del pensamiento, Barcelona, Argos Vergara.

- Punset, Eduardo (2005): El viaje a la felicidad. Las nuevas claves científicas, Barcelona, Destino. Disponible en: 
http://share.pdfonline.com/7452ba32fe774c4a9901f6506733f62e8/Punset, El\%20viaje\%20a\%20la\%20felicidad.pdf

- Reig, Ramón (1995): El control de la comunicación de masas, Madrid, Libertarias/Prodhufi.

- Reig, Ramón (2010): La telaraña mediática, Sevilla/Zamora, Comunicación Social Ediciones y Publicaciones.

- Reig, Ramón (2011): Los dueños del periodismo, Barcelona, Gedisa.

- Reig, Ramón (Director) y Mancinas-Chávez, Rosalba (Coordinadora) (2013): Educación para el mercado, Barcelona, Gedisa.

- Serrano, Pascual (2010): Traficantes de información, Madrid, Foca.

- Turner, Jonathan H. (2000): On the origins of human emotions a sociological enquiry into the evolution of human affect, California, Stanford University Press.

- Uña Juárez, Octavio, Fernández Fernández, Maximiliano y Fernández Camacho, Carmen (2013): "De todos y de ninguno: estructura de los procesos en la creación de opinión pública", en Álvarez, Jesús Timoteo (Investigador Principal): Neurocomunicación: Gestión de la Comunicación Social basada en las Neurociencias, Proyecto de Investigación CSO2011-28099. Informe 2012 Plan Nacional de I + D, Ministerio de Economía y Competitividad: Secretaría de Estado de Investigación, Desarrollo e Innovación.

- VV.AA. (2004): Historia Universal. Volumen 1. Los orígenes, Madrid, Salvat/El País.

\section{Notas}


${ }^{1}$ Ver: http://www.elmundodewayne.es/2011/11/02/nuevos-horizontes-de-la-comunicacion-en-la-erade-la-digitalizacion-y-la-globalizacion/. Consultado, 15/10/2013.

${ }^{2}$ Véase: http://www.youtube.com/watch?v=GOEy5ahVJEc. Consultado en septiembre de 2013.

${ }^{3}$ http://www.hispanidad.com/Exclusivas-prensa/la-caixa-estudia-crear-un-gran-hlding-con-susparticipadas-20130429-156278.html, 28/4/2013.

REDMARKA UIMA-Universidad de A Coruña - CIECID

Año VI, Número 11, (2013), v1 pp. 99-123

http://www.redmarka.org/

ISSN 1852-2300 